\title{
Analysis of Old Fitness Design and Operation of Medium-sized and Small Stadiums in Cold Regional Cities
}

\author{
Taking Harbin as an Example
}

\author{
Changhe Wang \\ School of Marxism \\ Zhejiang University \\ Hangzhou, China
}

\begin{abstract}
The elderly in cold regional cities are limited by the weather conditions to a large extent in terms of their outdoor physical fitness activities in winter. The promotion of old fitness design and operation of indoor sports facilities can improve the environmental conditions for elderly to do physical exercises in winter effectively and motivate their enthusiasm for physical fitness. The medium-sized and small stadiums have obvious advantages in the aspects of old fitness design and operation, give play to their role and value in physical fitness for the elderly, and create more appropriate physical fitness environment for the elderly. As a result, they are the inevitable trend for the development of medium-sized and small stadiums in cold regional cities in the future. Relevant data are obtained for this paper through actual investigation, and with these data, the practical experience and problems of old fitness design and operation of medium-sized and small stadiums are analyzed and summarized systematically in this paper, and the arguments and enlightenments are provided for relevant studies in the future.
\end{abstract}

Keywords-old fitness; design and operation; cold regional cities; medium-sized and small stadiums

\section{INTRODUCTION}

With the rapid development of China's social economy, the system for urban national fitness is improved constantly. Physical exercise is playing important role in the elderly people's life. The elderly in cold regional cities are limited by weather conditions to a large extent in terms of outdoor physical fitness activities in winter. On the one hand, winter lasts longer in cold regional cities, and the cold weather conditions and heavy air pollution make the outdoor environment not appropriate for the elderly to stay for a long time and to do exercises. On the other hand, the problems such as excessive ticket price, lack of facilities, low environment comfort degree and lack of indoor fitness sites, which are caused by lack of indoor sports facilities and the relative negligence of elderly people's demand by various indoor physical fitness places in the aspects of operation management, functional configuration and space organization, are very common. These are of adverse influence on the elderly in terms of their indoor physical fitness in winter. The promotion of old fitness design and operation of indoor sports facilities can improve the environmental conditions for the elderly to do physical exercises in winter effectively and motivate their enthusiasm for physical fitness.

The government constantly strengths the supportive measures for national fitness in the rapid development of China's sports undertaking, and indoor physical fitness is playing more and more important role in the life of the elderly. It is an inevitable trend for the elderly in cold regional cities to participate in indoor physical fitness in winter. Medium-sized and small stadiums are of obvious advantages in terms of old fitness design and operation, and give play to their role in the physical fitness of the elderly in cold regional cities. These stadiums pay attention to the comprehensive consideration of old fitness factors in the course of design and operation, which can create more appropriate physical fitness environment for the elderly, so as to promote the healthy and vigorous development of the sports for the elderly.

\section{CAUSES FOR THE DEVELOPMENT OF OLD FITNESS OF MEDIUM-SIZED AND SMALL STADIUMS IN COLD REGIONAL CITIES}

The old fitness development of medium-sized and small stadiums in cold regional cities is driven by internal causes and external causes. As for the internal causes, with the improvement of living standard, physical exercise is playing more active role in elderly people's life. At present, the sports life of the elderly is presenting the development trend of pursuing high quality and diversity. In the cold regional cities, the elderly have larger demand for indoor physical fitness in winter. Taking full advantage of the characteristics of mediumsized and small stadiums, such as spreading widely in cities and closing to the public's life, to improve the old fitness quality is of very important significance for promoting the development of sports for the elderly. As for the external causes, in order to promote the development of sports in cities, China has issued a series of policies and regulations to guide and improve national fitness, and lead the construction of urban sport facilities shifting to public physical fitness. The sports for elderly people will inevitably cause wide public 
concern under the circumstances of increasing intensification of old aging. The deepen thinking of old fitness and the establishment of more appropriate physical fitness platform for the elderly in the process of construction and operation of indoor sport facilities, such as stadiums and gymnasiums, are bound to be the tendency of urban sport facilities in the future, and the important link for constant improvement of national fitness system. In this paper, the causes of old fitness development of medium-sized and small stadiums in cold regional cities are summarized as follows:

\section{A. Unique Advantages of Medium-sized and Small Stadiums in Terms of Old Fitness Design and Operation}

The first is the scale and mathematical advantage. With the rapid development of China's national fitness, the construction mode of medium-sized and small stadiums is increasingly mature with significant improvement in quantity and scale. Old fitness design and operation require medium-sized and small stadiums to take the demand of the special group of elderly people into full consideration based on meeting basic functional requirements, to conduct overall planning of the building's planning, operation management, site selection and layout, functional space design and other aspects according to elderly people's physical and mental characteristics, behavioral habit and thinking mode, so as to provide the elderly with targeted high quality services. Medium-sized and small stadiums have relative low requirement for site selection and standard of construction in comparison with large scale stadiums, and have the advantages such as small area, widespread, large quantity and closer to community life. Therefore, these mediums can provide more convenient services for the elderly. The second is operation management advantage. It takes relative low cost for the operation management and maintenance of medium-sized and small stadiums compared with the large scale stadiums. Most of the rooms can offer all-weather open, which is easier to satisfy the physical fitness demand of different groups including the elderly, and to realize the composite use of stadiums. In addition, the charge of medium-sized and small stadiums is not high, which can attract more consumers, forming favorable interaction between stadium operation and public consumption. The third is function positioning advantage. Medium-sized and small stadiums mainly undertake the activities such as public recreation and physical fitness in addition to holding competitions, which is different from large scale stadiums which mainly hold large scale recreational and sports activities. With the vigorous development of China's sports and the improvement of public's physical fitness awareness, people's requirement for physical exercises has shifted to laying equal stress on appreciation and participation from just focusing on competition appreciation. The number and scale of the finished urban stadiums can no longer satisfy public's increasing physical fitness demand. Under such circumstances, the functional positioning of medium-sized and small stadiums should pay more attention to public's demand for physical fitness. The fourth is spatial layout advantage. The playing halls of medium-sized and small stadiums occupy a relative small area and have relative simple architectural structure. As a result, the limitation of structural span and appearance on spatial layout and streamline distribution design is relative small. With more flexible space division and stronger adaptability, such medium-sized and small stadiums are more adaptive to make division and transformation of space in accordance with elder people's physical and mental characteristics, so as to design more appropriate functional module and spatial layout.

\section{B. Increasing Demand of Elderly People for Sport Exercises}

From a long-term point of view, indoor and multiple sports are bound to the future of elderly people's sports life. Active participation in indoor sports can effectively reduce the adverse influence of weather conditions on the elderly in terms of their physical fitness, and encourage them to be involved in various sport items, thus to make their life quality be improved effectively. For one thing, elderly people have higher demand for physical exercises with the improvement of health awareness. Particularly, elderly people's exercises will be reduced greatly in winter, and there will be high incidence of various diseases along with the reduction of physical exercises. The varied and colorful indoor sports can make up the harmful influence resulted by deficiency of outdoor activities in winter effectively, help the elderly to improve physical function, withstand various diseases and enrich their daily life. For another, physical exercises still play the role of driving elderly people's social life actively. Most elderly people are at leisure after retirement, and thus they are easy to feel lonely. When winter comes, elderly people often stay at home with their opportunities to contact with other being significantly being reduced. The participation in indoor sports will enable the elderly to be physically strong, and can also create more opportunities for them to communicate with others, get acquainted with more people of about the same age and having similar tastes and interests, so as to help them to integrate into the social life.

\section{Promotion by National Policies and Regulations}

In order to promote smooth development of national fitness project, China has issued a series of policies and regulations within the recent ten years. A lot of guidelines and suggestions are proposed for the construction of public sports facilities and the promotion of development of sports for the elderly in the cities. In addition, explicit requirement of integrating old fitness factors into the process of urban sports facilities construction is also put forward. It is the significance of relevant national policies and regulations to develop physical fitness for the elderly, to make innovation of sports items and methods for elderly people, and to provide more physical fitness platforms for the elderly. The Outline of National Fitness Program (2011-2015) issued by the State Council points out clearly that "We should attach importance to the development of sports for the elderly; establish and improve sports association, sports fitness club, and sports fitness team; carry out regular physical fitness activities for the elderly; hold the sports and fitness conference for the elderly; make constant innovation of physical fitness items and methods which suit the characteristics of elderly people. Public sport facilities provide convenience and preferential conditions for the elderly to participate in sports activities. Moreover, educational institutions for the elderly should open sports courses; the recreation center for the elderly should set up the facilities 
suitable for the elderly to participate in physical activities, and the community service shall also give consideration to the physical fitness service for the elderly."

With the continuous increasing in the quantity of China's elderly people, sports for the elderly will be bound to occupy more important position in social development, and the degree of its development will become a significant index to measure the overall development level of sports. The integration of the consideration of old fitness factors into the course of mediumsized and small stadiums design and operation will establish better physical fitness service platform for the elderly and push forward considerable progress of the sports for the elderly.

\section{FIELD INVESTIGATION AND CASE ANALYSIS OF MEDIUM-SIZED AND SMALL STADIUMS IN HARBIN}

The author carried out field investigation of medium-sized and small stadiums in Harbin during 2014 to 2016, with investigated objects including more than 20 various types of medium-sized and small stadiums at district level, community level, or those in colleges and universities as well as in enterprises and institutions. The practical experience and main problems in the old fitness development of medium-sized and small stadiums are summarized through investigation and research on their operation management, site layout, functional space, external environment design and exercise status of the elderly, and discuss the room and potential for their improvement. In this paper, Harbin Municipal Stadium is selected to be analyzed with emphasis as an example.

\section{A. Site Selection Reason}

As one of the most important public sport facilities of Harbin, this stadium has successfully hold about one hundred times of international, national, provincial and municipal competitions since it is constructed, and it also provide a good service platform for citizen's physical fitness. This stadium can make explorations and practices according to elderly people's physical and mental characteristics and sport demand especially in the aspects of operation management and functional layout, which creates more convenient physical fitness services for the elderly, and plays the role of demonstration in old fitness development of medium-sized and small stadiums.

\section{B. Site Layout}

This stadium is located in the yard of Eight District Sports Center, Daowai District, Harbin City, being adjacent to Harbin Hockey Hall, Swimming Pool, Winter Sport Training Center and People's Stadium. There are citizen residential areas and perfect traffic system around it, which is convenient for the elderly people to get to. Outdoor activity playgrounds are equipped around the building, and many elderly people do exercises in it, as shown in "Table I".

\section{Operation Management}

In order to create more physical fitness opportunities for the elderly and to improve their enthusiasm for physical exercises, this stadium makes corresponding adjustment and offers favorable conditions according to elderly people's actual need in terms of operation time, ticket price and other aspects. For instance, the stadium opens 2-3 hours in advance according to elderly people's characteristics of loving morning exercises. The business hours are 5:30-22:00 from May 1st to September 30th, and 6:00-22:00 from October 1st to April 30th next year. Early in the morning, the sites for basketball, badminton and other activity places are shifted to the areas for dancing, Tai Ji and other sports of the elderly. Thereafter, these sites resume their original functions. In addition, according to the differences in people's exercise time at working days, weekends and vacation, the stadium adjusts the utilization of various functional spaces in a flexible way, and the composite use of spaces is realized. With respect to ticket price, the manager implements multiple favorable policies on the elderly. For instance, the year card system of 360 yuan/person is implemented on table tennis, and elderly people who have year card can go to the stadium to play table tennis at any time without limitation, which is obviously preferential compared with the ordinary charge standard of 10 yuan/hour. However, there are also some insufficiencies in stadium's operation management. For example, the stadium leases part of the space to contractors as clubs, and the price standard is greatly improved, which has caused certain limitation to public's wide participation in physical activities. Moreover, many training places are not open to the outside and left unused for a long time, so the stadium is not fully used. In addition, the publicity of it by manager is insufficient and most elderly people do not know the specific price policies of the stadium. Therefore, these conditions are the problems to be solved by mediumsized and small stadiums in their future operation process. 
TABLE I. VIEW OF INTERNAL SPACE OF HARBIN MuNicIPAL STAdium

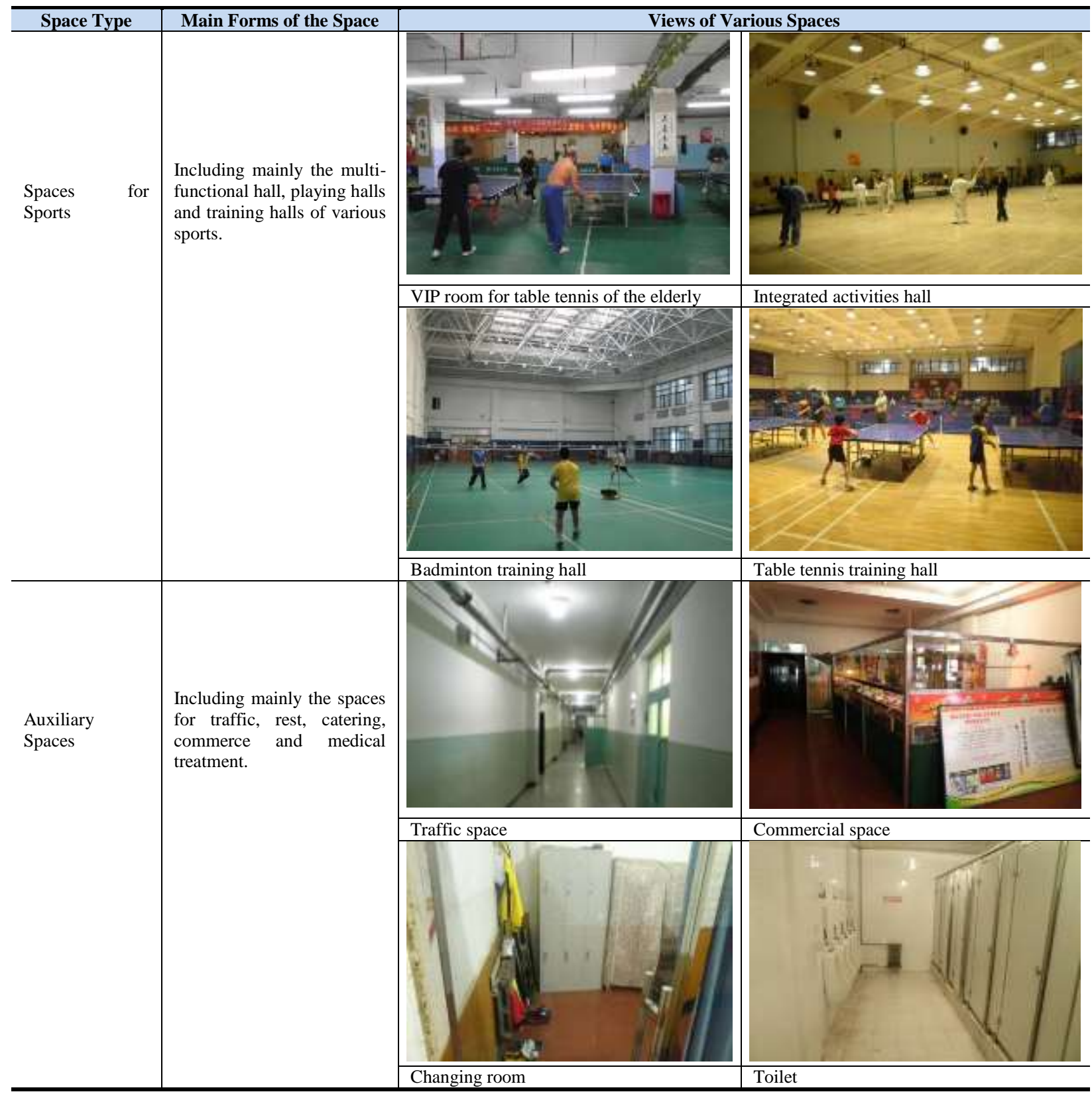

\section{Functional Layout}

This stadium is composed of many halls for competition, training, badminton, table tennis, apparatus, weight lifting as well as multi-functional hall, enabling the training and competition of multiple items to be conducted simultaneously. In addition, the meeting room, VIP room, lounge, small scale commerce and other multi-functional service spaces are equipped. In order to close to the public's sports life, many halls for badminton and table tennis are added in this stadium, and these functional spaces are divided properly via vertical partition and horizontal partition, to form the relative independent functional partitions. For the convenience of elderly people's utilization, the stadium arranges the table tennis club exclusive for the elderly at the position near the main stairway at first floor underground, to form the relative independent activity partitions, and reduce mutual interference with other areas. Early in the morning, the badminton hall with large area at the first floor underground is shifted into multifunctional space for the elderly to play Tai $\mathrm{Ji}$, dance, martial arts and other collective activities, which can satisfy elderly people's demand for collective activities, and can effectively reduce interference to elderly people by others, so as to create independent and comfortable environment for the elderly.

However, there are many insufficiencies in the old fitness design and operation of the stadium due to limitation of various factors including construction scale and operation investment. The first is the lack of functional space variety. The interior of the building is short of necessary spaces for 
association, cultural recreation, and catering, medical service as well as other supporting spaces and facilities, so it is difficult to satisfy elderly people's demand for multiple activities besides exercises. Second, most sites are still left in idle and are not used fully. The spaces which have realized composite use inside the stadium haven't reached one third of the total construction area; part of the training halls are not open to the public, but left in idle for a long time, so if these spaces can be utilized fully, the operation pressure of other functional spaces may be shared effectively, thus the utilization efficiency of space is improved. Third, the old fitness in terms of detail treatment is not designed thoroughly, for instance, the barrier-free design inside the building is not very perfect, the elevator and barrier-free toilet and other facilities are not arranged; another example, the arrangement of activity areas for the elderly at first floor underground also has some problems, such as ventilation and lighting, although it provides relative independent partitions. Particularly, the problem of ventilation reduces the comfort level in the space.

\section{MAIN PROBlems to Be SOlVEd FOR OLd FITNESS DESIGN AND OPERATION OF MEDIUM-SIZED AND SMALL STADIUMS}

\section{A. Problems Existing in Site Selection and Layout}

The first is that it is hard to get to the construction site. The functional positioning of medium-sized and small stadiums is partial to public sports, so the building site should be selected at the area with convenient traffic to make it easy for the residents to get to. However, with the limitation of multiple factors including municipal planning, land pressure and economy burden, currently, the medium-sized and small stadiums in cold regional cities still have difficulties in taking public utilization as the major basis for building site selection. The construction of many medium-sized and small stadiums still has the problems of remote location and being apart from municipal traffic system, making the stadiums break away from public's life due to its location or inconvenient traffic. With respect to the elderly in cold regional cities, the convenient traffic is the determining factor influencing their travelling, so the excellent traffic conditions will vigorously promote the elderly people's enthusiasm to participate in the indoor physical exercises. Second, the quantity of stadiums is insufficient and the scale is too small. At present, mediumsized and small stadiums in cold regional cities are mostly distributed in campus or enterprises or institutions, with very limited quantity of stadiums are constructed independently in communities. The medium-sized and small stadiums are mainly developed and operated jointly by government and school or enterprises or institutions. The medium-sized and small stadiums with limited quantity have to undertake the tasks of holding competitions and daily teaching; in addition, they should also take the public's physical exercises into consideration; under such conditions, the stadiums are overstretched and have difficulties in balancing the conflicts among various parties. Consequently, many stadiums choose to reduce their degree of openness to the public. In addition, many buildings of medium-sized and small stadiums were built years ago, having the problems of small construction scale or lack of complete supporting facilities, making it difficult to realize the composite use of functional space, and cannot conduct the specific old fitness design transformation and operation management according to elderly people's physical and mental characteristics.

TABLE II. IDLED SPORT FIELDS WITHIN THE STADIUM

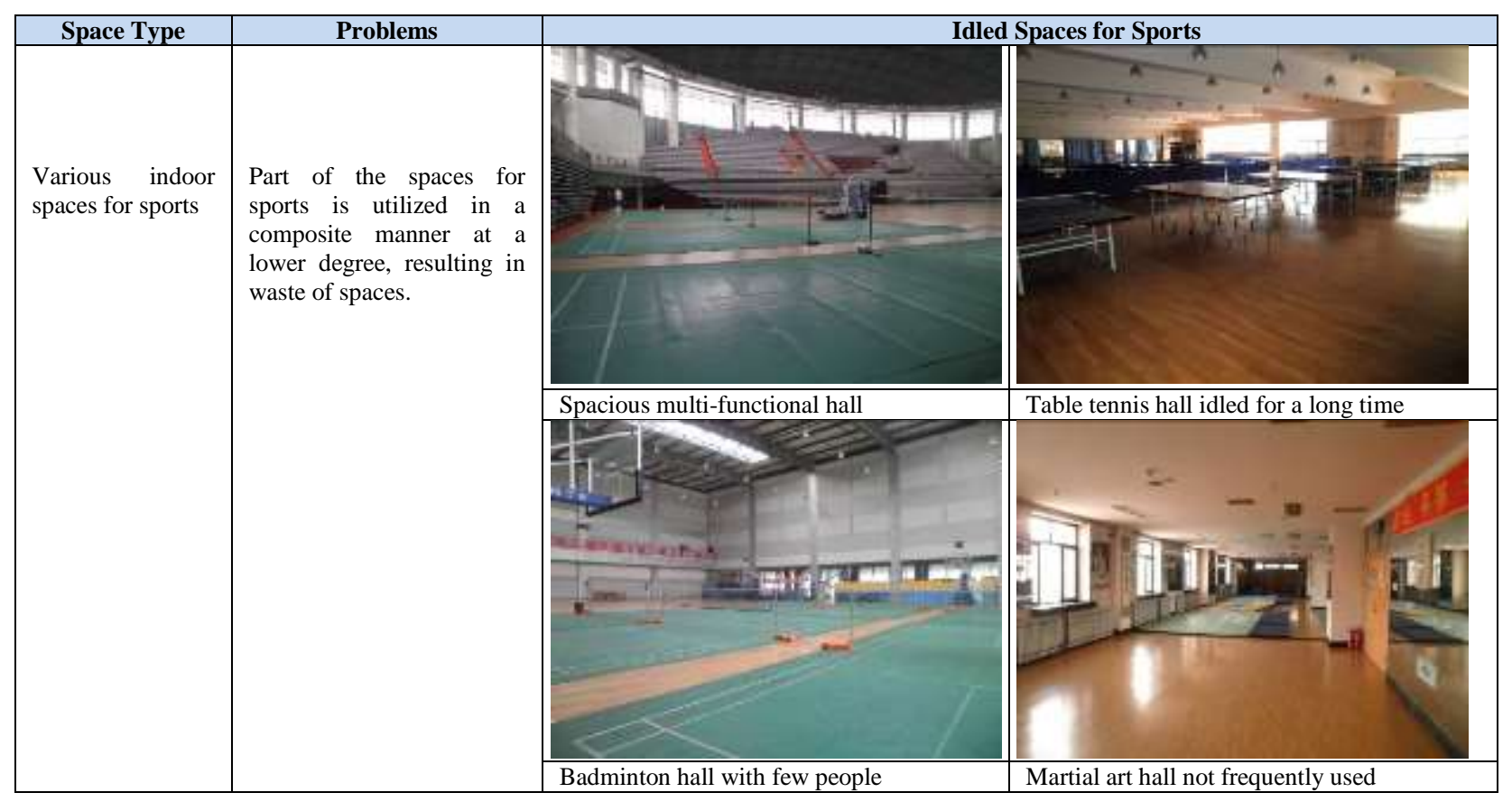

Table source: made by the author; picture source: shot by the author during investigation. 


\section{B. Problems Existing in Operation Management}

First of all, the ticket price is too high. It is found during the investigation of medium-sized and small stadiums in Harbin that, most stadiums charge according to the standard of 20-30 yuan/hour, and seldom implement preferential policies on the elderly. Particularly, many stadiums lease part of their spaces to individual contractors, which increases the charging standard further, and the charges of some sports even reach to more than one hundred yuan per hour, which make them the nobleman physical fitness sites in the true sense. There is a large gap between such expensive ticket price and the average income level of the elderly, so most of the elderly keep the stadiums at a distance. The second is the poor composite use of the sites. It is found through investigation that the problem of rigid utilization mode of the sites exists in the actual operation of many medium-sized and small stadiums. The manager controls site utilization mechanically, and cannot adjust in a flexible way according to different people's different exercise demand, which has reduced the complexity and flexibility of stadium utilization and caused idleness and waste of sites. Taking the morning exercises of elderly people in cold regional cities as an example, in winter, many elderly people do morning exercises during 5 am to $7 \mathrm{am}$, while most of the medium-sized and small stadiums open at 8 am in winter, which means that while elderly people are doing morning exercises in cold conditions, those stadiums with comfortable environment are left unused, as shown in "Table II". The third is insufficient publicity of stadium operation. The operation and maintenance of medium-sized and small stadiums needs a lot of funds. As a result, to maintain daily operation and improve utilization efficiency, stadiums should try their best to attract different sport consumption groups and form the good interaction relationship with the consumers. However, the lack of publicity by medium-sized and small stadiums at present make them have difficulties in attracting larger sport consumption group, just as in the investigation, many elderly people indicate that they do not know the charging conditions of stadiums currently. This is also an important reason causing many stadiums' breaking away from social public after they are constructed and the operation depression.

\section{Problems Existing in Functional Space Design}

First, the detailed design of functional space is not made thoroughly enough. At present, the functional space arrangement of medium-sized and small stadiums is generally short of refined thinking, and the extensive design mode with rigid uniformity has difficulties in conducting thorough and detail research according to characteristics of various people, and eventually it will cause reduction in flexibility and adaptability of building functional space. It is found through investigation that, most of the stadiums are not able to make corresponding design and transformation according to elderly people's physical and mental characteristics. The elderly participating in activities share the space for exercises and auxiliary space with other people, which will bound to result in influence and interference of different degree on them. In addition, some stadiums use the floor materials with poor elasticity and non-skid property, reducing the safety of elderly people in walking and doing exercises, or the prompt identifications are absent at sensitive positions, such as stairway, step and corner, weakening the guidance of space environment. Another example, necessary facilities for having a rest, such as chairs, are not arranged in the narrow and long traffic space, or some rooms loved by the elderly are arranged at the remote position. The reasons of these problems are that designers did not make detailed consideration of the space detail, and they failed to carry out effective micro transformation of space environment according to people's characteristics, resulting in lack of humanity in space environment.

Second, the variety of service functional space is insufficient. Functional space design of medium-sized and small stadiums often pays more attention to the satisfaction of people's demand for physical exercises, and neglects users' other demand besides sports, such as association, recreation and rest. The spatial layout of building also highlights the subject position of space for exercises, yet puts other service spaces at secondary position or neglects them, which conditions intensifies the absence of service space variety. As for the elderly, participating in physical exercises is the effective method for physical fitness, communication, recreation and consumption. As a result, the stadium is required to be equipped with spaces and facilities for association, recreation and rest while providing high quality physical fitness environment. For instance, elderly people often need more rest to adjust physical agility in the process of physical fitness, and they are vulnerable to injury and disease. Therefore, a certain quantity and scale of rooms for rest and medical treatment should be equipped in the stadium.

Third, barrier-free design is not perfect enough. The perfect barrier-free system of horizontal traffic and vertical traffic is very important for the elderly. However, in the actual construction process, the barrier-free design of most mediumsized and small stadiums is not perfect enough. It is found in the investigation that only a small number of stadiums arrange the traffic facilities such as elevator, barrier-free staircase. Many buildings are equipped with barrier-free ramp at the entrance, but the barrier-free treatment is not made at the places with altitude difference within the building, or the barrier-free toilet and other facilities are not equipped. Some barrier-free facilities are arranged with obvious perfunctory attitude to comply with the requirement of relevant regulations. The size and specification differ greatly from those specified in the standard and requirement, making the facilities unable to be used effectively. All these bring about inconveniences to the elderly in stadiums. 
TABLE III. PART OF INTERNAL ENVIRONMENT OF THE STADIUM

\begin{tabular}{|l|l|l|}
\hline \multicolumn{1}{|c|}{ Space Type } & \multicolumn{1}{|c|}{ Problems } \\
$\begin{array}{l}\text { Detail treatment of the } \\
\text { main indoor spaces for } \\
\text { traffic and rest }\end{array}$ & $\begin{array}{l}\text { Some stadiums are short of } \\
\text { thorough and detailed } \\
\text { thinking in terms of space } \\
\text { design, detailing, and } \\
\text { facilities and equipment, } \\
\text { influencing the quality and } \\
\text { comfort level of } \\
\text { environment. }\end{array}$
\end{tabular}

Fourth, the technical facilities are equipped at lower level. The construction standard and fund investment of mediumsized and small stadiums is lower than that of large scale stadiums. In order to save the daily operation cost of stadiums, many facilities are left unused for a long time. For example, some mechanical ventilation and lighting facilities inside the stadiums are only put into use when holding competitions, yet they seldom give play to their utility at ordinary times. In addition, the design of natural ventilation and lighting of the buildings is not perfect, and this may reduce the environment quality and comfort level greatly inside the stadium, as shown in "Table III". Some conditions like the traffic route in some stadiums is too long with dim light, making it inconvenient for elderly people to walk; the natural ventilation effect of stadium is not perfect, and mechanical ventilation facilities are rarely used, so the stadium is not well ventilated with heavy peculiar smell; the materials with poor thermal insulation performance are used on the top surface of the hall for exercises, and condensation and dripping will appear in winter, influencing the normal use of the site; the acoustical isolation performance of the isolating material of each unit space is poor, causing mutual sound interference to the adjacent spaces.

\section{CONCLUSION}

The old fitness design and operation of medium-sized and small stadiums require taking the elderly people's characteristics and demand into full consideration in the links such as site selection and layout, operation management, functional design. For one thing, designers should excavate the physical and mental characteristics and movement regularity of the elderly deeply on the basis of actual investigation, take elderly people's demand of exercises, recreation, rest, association and other different types of activities into consideration as fully as possible, adopt corresponding design countermeasures, organize functional partition scientifically, design the space with reasonable detail and proper size, to make various functional spaces more varied and colorful as well as more adaptive; for another, the stadiums should make corresponding adjustment and changes in combination with elderly people's movement regularity and actual demand in the aspects of business hours and composite use of the site, to establish appropriate physical fitness platform for them, so as to provide powerful support and durable driving force for the vigorous development of sports for the elderly.

\section{REFERENCES}

[1] State Council. Notice on Printing and Distributing the National Fitness Plan (2011-2015) [EB/OL]. (2011-02-24) [2018-05-15]. http://www.xici.net/d144148850.htm.

[2] The Ministry of Construction of People's Republic of China. JGJ 312003. Design Code for Sports Building [S]. 2003.

[3] Mei Jikui et al. Design of Modern Stadium [M]. Heilongiiang: Heilongjiang Science and Technology Press, 1999.

[4] Mei Jikui et al. Study on Design of Sports Building [M]. Beijing: China Architecture \& Building Press, 2010.

[5] Zhou Yanmin et al. House for the Aged [M]. Beijing: China Architecture \& Building Press, 2011.

[6] (Japan) Juridical Person, Residential Foundation for the Elderly. Handbook for Elderly Residential Design [M]. Translated by Boloni Finishing Institute, China Institute of Building Standard Design \& Research. Beijing: China Architecture \& Building Press, 2011. 